\title{
Hand hygiene management among nurses: collective health challenges
}

\author{
Gestão do procedimento higiene das mãos por enfermeiros: desafios para saúde coletiva
}

Gestión del procedimiento de la higiene de las manos por enfermeros: desafíos para la salud colectiva

\author{
João Manuel Graveto', Cristina Santos', Paulo Santos Costa', Elisabete Fernandes', \\ Susana Alarico", Nádia Osório"II, Helena Albano"v", Vânia Oliveira"II \\ 'Escola Superior de Enfermagem de Coimbra. Coimbra, Portugal. \\ "Universidade de Coimbra. Coimbra, Portugal. \\ I'I Instituto Politécnico de Coimbra. Coimbra, Portugal. \\ vv Universidade Católica Portuguesa, Escola Superior de Biotecnologia. Porto, Portugal.
}

\begin{abstract}
Graveto JM, Santos C, Costa PS, Fernandes E, Alarico S, Osório N, et al. Hand hygiene management among nurses: collective health challenges. Rev Bras Enferm [Internet]. 2018;71(Suppl 1):562-7. [Thematic Issue: Contributions and challenges of nursing practices in collective health] DOI: http://dx.doi.org/10.1590/0034-7167-2017-0538
\end{abstract}

How to cite this article:

Submission: 30-07-2017 Approval: 16-10-2017

\begin{abstract}
Objective: To describe the determining factors in hand hygiene management among nurses and identify associated collective health challenges. Method: Cross-sectional descriptive study. Data were collected using a questionnaire that was applied in four internal medicine units of a hospital of reference in Portugal. Results: The sample was composed of 50 nurses aged 26 to 55 years (mean age of 34.88 years); $80 \%$ were women, $58 \%$ had a Bachelor's degree, and had 5-30 years of nursing practice $(\bar{X}=11.94 ; \pm 5.92)$. The vast majority of nurses $(90 \%)$ reported complying with the existing recommendations on hand hygiene in pre-established moments. However, none of the nurses were able to identify all the moments for hand hygiene using water and soap or alcohol-based handrub. Conclusion: This study shows that continuous training, adequate materials/structures in the units, and redesigned administration/supervision practices are determining factors to achieve higher levels of adherence to hand hygiene among nurses, as well as increased quality and safety in care delivery, which is a current collective health challenge.

Descriptors: Health Services Administration; Hand Hygiene; Nurses; Infection Control; Public Health Nursing.
\end{abstract}

\section{RESUMO}

Objectivo: Descrever fatores determinantes na gestão da higiene das mãos por Enfermeiros e identificar desafios inerentes para a saúde coletiva. Método: Estudo descritivo-transversal. Dados coletados por questionário em quatro unidades de medicina interna de um hospital de referência em Portugal. Resultados: incluídos 50 enfermeiros, idade média 34,88 anos (entre os 26 e 55 anos), $80 \%$ sexo feminino, $58 \%$ são licenciados e exercem funções entre $5-30$ anos ( $\bar{X}=11.94 ; \pm 5.92)$. Destes, $90 \%$ considera respeitar as recomendações existentes sobre higiene das mãos nos momentos estipulados para o efeito. Porém, nenhum dos momentos para a realização deste procedimento, com água e sabão ou solução antissética de base alcoólica, foi identificado por todos os enfermeiros. Conclusão: Contribuições como formação contínua, adequação dos materiais/estruturas das unidades e reconstrução de práticas por gestores/supervisores emergem neste trabalho como fatores determinantes para atingir níveis superiores de adesão à higiene das mãos por enfermeiros, de qualidade e segurança, desafio atual para a saúde pública.

Descritores: Gestão de Serviços de Saúde; Higiene das Mãos; Enfermeiras e Enfermeiros; Controle de Infecções; Saúde Coletiva.

\section{RESUMEN}

Objetivo: Describir los factores determinantes en la gestión de la higiene de las manos por enfermeros e identificar los desafíos inherentes para la salud colectiva. Método: Estudio descriptivo-transversal. Los datos se recogieron mediante un cuestionario en cuatro unidades de medicina interna de un hospital de referencia en Portugal. Resultados: se incluyó a 50 enfermeros con una edad media de 34,88 años (entre los 26 y 55 años), el $80 \%$ del sexo femenino, el $58 \%$ son licenciados y desempeñan sus funciones de 5 a 30 años $(\bar{X}=11.94 ; \pm 5.92)$. De ellos, el $90 \%$ considera que respeta las recomendaciones existentes 
sobre higiene de las manos en los momentos estipulados para tal efecto. Sin embargo, los enfermeros no identificaron ninguno de los momentos para realizar este procedimiento, con agua y jabón o solución antiséptica de base alcohólica. Conclusión: Las contribuciones como formación continua, adecuación de los materiales / estructuras de las unidades y reconstrucción de prácticas por gestores / supervisores emergen en este trabajo como factores determinantes para alcanzar niveles superiores de adhesión a la higiene de las manos por enfermeros, de calidad y seguridad, un desafío actual para la salud pública.

Descriptores: Gestión de Servicios de Salud; Higiene de las Manos; Enfermeras y Enfermeros; Control de Infecciones; Salud Colectiva.

CORRESPONDING AUTHOR João Manuel Graveto E-mail: jgraveto@esenfc.pt

\section{INTRODUCTION}

Healthcare-associated infections (HAls) are infections occurring in a patient during care delivery in a hospital or other healthcare facility, which was not present or incubating at the time of admission ${ }^{(1)}$. As a collective health challenge, HAls are a barrier to proper treatment, a leading cause of morbidity and mortality, affecting hundreds of thousands of people each year, and a cause of increased consumption of hospital and community resources, of which around one-third could be prevented ${ }^{(1-2)}$. The literature highlights other determining factors for this challenge, including complex gaps in health policies, infrastructures, organization, and knowledge and health professionals' ineffective practices and behaviors ${ }^{(3)}$. Therefore, HAI prevention and control measures should be implemented to ensure the safety of both patients and professionals. These measures are called standard precautions and include hand hygiene ${ }^{(4)}$.

Healthcare professionals' hands are the most common transmission route of infectious agents causing HAls, although transmission is complex and multifactorial ${ }^{(5-6)}$. However, this topic remains relevant since the global rates of compliance with this standard precaution are still surprisingly low: below $40 \%$, on average $\mathrm{e}^{(7)}$. In this sense, every professional must perform hand hygiene correctly, either through hand washing or disinfection using alcohol-based handrub according to the existing guidelines ${ }^{(2)}$.

In Portugal, the prevalence rate of hospital-acquired infections $(10.5 \%)$ is higher than the European average $(6.1 \%)$, resulting in an absolute number of 4,606 deaths ${ }^{(8)}$. According to the latest data from the Audit Report on Standard Infection Control Precautions (Relatório de Auditoria às Precauções Básicas em Controlo da Infeção), professionals' level of adherence to hand hygiene has increased to $70.3 \%{ }^{(9)}$. Despite the increasingly positive trend, these figures are still far from the goal set out by the World Health Organization: $100 \%$ of professionals' adherence to this procedure ${ }^{(9)}$.

Healthcare units should promote an institutional culture of safety, giving priority to adequate hand hygiene practices. This culture must be reinforced in the existing management and training programs and the operational plans for infection prevention and control ${ }^{(10)}$. Interestingly, only $1 \%$ of the literature on this topic falls within the scientific field of nursing, which is both surprising and alarming since nurses are the largest group of health professionals ${ }^{(11)}$.

In Portugal, at the time of this study, only a few publications addressed nurses' management of hand hygiene procedures, which justified filling in this gap.

\section{OBJECTIVE}

This study aimed to describe the determining factors in hand hygiene management among nurses working in Internal Medicine units of a hospital located in the Central region of Portugal, as well as to identify potential collective health challenges.

\section{METHOD}

\section{Ethical considerations}

This study was submitted to the Ethics Committee of the institution under analysis and approved on 20 January 2017. All participants signed the Informed Consent Form for Participation.

\section{Study design, location, and period}

A cross-sectional descriptive study was conducted. In Portugal, the incidence proportion and rate of HAls in Internal Medicine units is significant when compared to other types of care units $^{(12)}$. Thus, data were collected between March and April 2017 at four Internal Medicine units of a hospital located in the Central region of Portugal. This hospital is a corporate entity endowed with administrative, financial, and patrimonial autonomy, and integrates the care delivery network of the Portuguese National Health Service (Serviço Nacional de Saúde).

\section{Population and inclusion/exclusion criteria}

The target population of this study was selected upon consultation with the Head Nurses and Service Directors of each unit under analysis. A total of 115 nurses were identified. The following inclusion criteria were applied: (i) nurses holding, at least, the Bachelor's degree; (ii) nurses providing direct care to patients; (iii) nurses working in each unit at the time of data collection; and (iv) nurses who expressed their will to participate by signing the informed consent form.

\section{Study protocol}

An extensive literature review on the topic revealed the lack of a specific instrument to analyze nurses' hand hygiene management, both at the national and international levels. Therefore, thematic contents were extracted from national and international normative documents of reference. The questionnaire was designed and later validated using a focus group which was selected from a heterogeneous sample composed of nurses of different ages, education levels, and professional responsibilities $(n=2)$. As a result of this process, semantic changes were made to the questionnaire, which included the terminological and structural reformulation of ambiguous 
terms and questions, as well as the division of complex questions in two or more questions. Thus, in the first section of the instrument, nurses are asked about the human, material, and management/administrative resources at their unit, as well as about the nursing team's common practices for HAI prevention and control. In the second section, nurses were asked to describe how they manage the hand hygiene procedure and the factors influencing their behaviors and decisions.

Participants were selected using the convenience sampling technique. The head nurses introduced the research team to the nurses, who were then invited to participate in the study. Data were collected in a private room at each unit, thus ensuring the privacy of all people involved.

\section{Analysis of results and statistics}

This study analyzed the following variables: nurses' sociodemographic characteristics; nurses' perceptions of both individual and collective hand hygiene compliance, behaviors, and practices; and nurses' perceptions of the resources at the unit/institution that promote hand hygiene among health professionals. A database was created using the software IBM SPSS Statistics for Windows, Version 19.0, to gather and interpret all data, using descriptive statistics to determine the absolute and relative frequencies.

\section{RESULTS}

The final sample was composed of 50 nurses aged 26 to 55 years (mean age of 34.88 years), of whom $80 \%$ were women. In this sample, $58 \%$ of nurses held the Bachelor's degree, $16 \%$ were nurse specialists, $14 \%$ held a Master's degree, and $12 \%$ had completed a Postgraduate program. Participants had been working as nurses for 5 to 30 years, with a mean length of service of 7.54 years $( \pm 5.92)$.

When asked about their participation in specific training on HAls, $56 \%$ of nurses reported having had training opportunities through the hospital and $2 \%$ of them had this opportunity outside the institutional context. However, $42 \%$ of the nurses reported having received no recent training on infection prevention and control. All participants agreed that this training should be mandatory and integrated into the institutional training plan. When asked about the existence of a professional of reference for $\mathrm{HAl}$ prevention and control at their unit, all nurses (100\%) identified the "liaison" nurse. Only one participant identified the Head Nurse as playing a key role in this context.

As regards the hand hygiene procedure, $82 \%$ of participants reported that nurses' adherence in their unit was higher than $75 \%$, $8 \%$ believed that it ranged from 25 to $50 \%, 8 \%$ had no opinion, and $2 \%$ considered that it was below $25 \%$. However, when asked about their own adherence to the procedure, $90 \%$ of them reported performing it in $75 \%$ or more of the established moments, $8 \%$ in $25-50 \%$ of the moments, and $2 \%$ had no opinion.

Nurses were also asked about the specific moments for hand hygiene in order to understand their perceived level of adherence (Table 1). Most nurses identified the need to perform hand hygiene before a clean/aseptic procedure $(92 \%)$ and after touching a patient $(90 \%)$. On the contrary, the moment "after touching patient surroundings" was the least identified by participants (44\%).
Table 1 - Moments for hand hygiene as identified by nurses

\begin{tabular}{lc}
\hline \multicolumn{1}{c}{ Moments for hand hygiene } & $\begin{array}{c}\text { Percentage } \\
\mathbf{( N = 5 0 )}\end{array}$ \\
\hline Before a clean/aseptic procedure & $92 \%$ \\
After touching a patient & $90 \%$ \\
After body fluid exposure risk & $86 \%$ \\
Before touching a patient & $74 \%$ \\
After touching patient surroundings & $44 \%$ \\
\hline
\end{tabular}

With regard to the factors influencing nurses' decision about handwashing with soap and water, $92 \%$ of nurses reported washing their hands when they were visibly dirty or had been in contact with organic matter. Furthermore, 90\% of the nurses reported washing their hands after delivering care to patients with Clostridium difficile infection. As regards unit-specific factors, $34 \%$ of nurses highlighted that the lack of washbasins interferes with their decision about handwashing with soap and water, and $18 \%$ justified their decision with the lack of specific areas for hand drying inside the clinical area. At the individual level, $88 \%$ of nurses reported washing their hands before and after using sanitary facilities and $78 \%$ before and after meals. Interestingly, $12 \%$ of nurses forgot to perform this procedure and $32 \%$ choose not to wash their hands with soap and water due to lack of time.

As regards the factors that interfere with nurses' decision to use an alcohol-based handrub for hand hygiene, $64 \%$ reported using it before a clean/aseptic procedure and $62 \%$ after these procedures or when their hands had no visible dirt or organic matter. At the individual level, $42 \%$ of nurses reported that the lack of time interfered with their decision to use an alcohol-based handrub, 36\% avoided using it in case of hand injuries, 30\% did not use it due to the lack of dispensers in the clinical area, and $8 \%$ forgot to use it in their clinical practice.

The majority of nurses reported using no personal accessories during care delivery. However, $48 \%$ of nurses used rings, $6 \%$ used bracelets, $4 \%$ used a watch, and $2 \%$ used long-sleeve clothing other than their uniform. With regard to their nails, $85.7 \%$ reported using no product or accessory, $8.2 \%$ used gel/gel polish, and $6.1 \%$ used nail polish during care delivery.

When asked about the promotion of adherence to hand hygiene within the institution, $58 \%$ of participants agreed with the managers and administrators' role in this area, although $28 \%$ had no opinion on the matter. With regard to the importance of the internal auditors' role in the supervision of hand hygiene compliance and management, 52\% of nurses agreed with its importance, but a large percentage of them had no opinion on the matter (42\%). As regards aspects related to information and promotion, $62 \%$ of nurses agreed that the materials on hand hygiene (posters, leaflets, etc.) available in several locations at the unit are appropriate. As regards institutional guidelines on health professionals' hand hygiene, although $86 \%$ of nurses reported knowing these guidelines (in paper format), $10 \%$ of nurses are unaware of them. 


\section{DISCUSSION}

In this sample, $90 \%$ of nurses reported following the existing guidelines on hand hygiene in most of the established moments. In addition, they believe that the level of adherence is also high among the other nurses in the team (82\%). According to the Portuguese audit report ${ }^{(9)}$, these values are above the mean level of adherence among professionals in $2015(73.1 \%)$. As regards the level of adherence among nurses working in internal medicine units in Portugal, which have similar characteristics to those analyzed in this study, the report showed an adherence of $75.2 \%$ in $2015^{(9)}$.

Interestingly, this audit report showed that nurses are the professional group with the highest overall levels of adherence to hand hygiene, except in internal medicine units ${ }^{(9)}$. In this study, none of the nurses identified all moments for hand hygiene, giving distinct answers. Similarly, in a multicentric study with 638 nurses, inconsistent results were obtained at different moments for hand hygiene: hand hygiene compliance was higher "after body fluid exposure risk" and lower "after touching patient surroundings"(13). Other international studies have tried to explain these discrepancies by analyzing the behavioral factors influencing nurses' adherence to hand hygiene and found that hand hygiene is divided into two dimensions: inherent and elective $\mathrm{e}^{(14)}$. The inherent dimension applies to behaviors that are performed when hands are physically dirty or when they have been in contact with a body area considered to be "emotionally dirty" (e.g., the patient's groin and genitals) ${ }^{(14)}$. The elective dimension applies to behaviors that encompass all other potential hand hygiene opportunities (e.g., touching the patient's surroundings), based on each nurse's perception that, by not performing this procedure, he/ she is not compromising care delivery ${ }^{(14)}$.

It should also be noted that only half of the sample reported not using accessories during nursing care delivery. Despite the recommendations not to use them in the literature of reference $^{(8-9)}$, nurses continue to use rings $(48 \%)$, bracelets $(6 \%)$, and nail polish/gel (14.3\%).

As regards handwashing with soap and water, none of the nurses have identified all the established moments for hand hygiene. Rather, $78 \%$ of nurses washed their hands "before and after meals" and 92\% when their hands were "visibly dirty" or "contaminated with organic matter". Nurses identified the following factors influencing their adherence to hand hygiene: lack of washbasins inside the clinical areas (34\%), lack of time $(32 \%)$, and lack of specific areas for hand drying $(18 \%)$. Interestingly, these factors are consistent with the barriers identified by nurses in their units, namely architectural barriers, inadequate clinical materials, insufficient staffing, and excessive workload. However, $12 \%$ of nurses reported forgetting to perform this procedure at the established moments, thus revealing a personal component that may explain nurses' low level of adherence.

As regards alcohol-based handrubs for hand hygiene, the sampled nurses were less aware of their use. Only $64 \%$ of the nurses identified one of the established moments ("before a clean/aseptic procedure"). Similarly to international studies, these results can be explained by the factors identified by nurses as factors influencing the use of alcohol-based handrubs (e.g., the lack of time and lack of dispensers inside the clinical areas), which, in turn, point to some of the identified challenges, namely insufficient staffing and inadequate clinical materials ${ }^{(13-14)}$. However, it should be noted that a significant percentage of professionals does not use handrubs in case of hand injuries (36\%) or because they forget to use them $(8 \%)$. Interestingly, the results of this study on the use of alcohol-based handrubs in health units are below the national average, which reached $97.9 \%$ in 2015; however, the lack of dispensers in specific areas and the lack of infection control and prevention strategies were also observed nationwide ${ }^{(9)}$.

The majority of nurses agrees with the contribution of the managers and administrators of their institution to the promotion of hand hygiene adherence $(58 \%)$ and the role of internal audits $(52 \%)$, and is aware of the existence of internal guidelines on this procedure $(86 \%)$. However, professionals still show a lack of knowledge about the established moments and the compliance behaviors that they should adopt without affecting the quality and efficacy of the procedure. Taking into account that managers must identify and tackle these challenges ${ }^{(10)}$, it is worth noting that only $2 \%$ of sampled nurses identified the Head Nurse in their unit as a professional of reference for $\mathrm{HAl}$ control and prevention, while all nurses $(100 \%)$ assigned this role to the "liaison" nurse.

As regards training, different situations were observed since, although most nurses participated in training sessions for $\mathrm{HAl}$ control and prevention, a large percentage of the sampled nurses did not have the opportunity to receive training (56\% versus $42 \%$, respectively). Taking into account that $58 \%$ of these professionals hold a Bachelor's degree, and based on the evidence that confirms the need for nurses to receive continuous training on hand hygiene ${ }^{(5,11,13-14)}$, the lack of training opportunities may explain why some results fall short from what would be expected regarding their knowledge and behaviors concerning hand hygiene. In Portugal, the number of trained professionals is gradually increasing: in 2015, 36.3\% of health professionals received training on hand hygiene ${ }^{(9)}$. Therefore, unit managers and institutional administrators should ensure that nurses receive adequate training about $\mathrm{HAI}$ standard control and prevention precautions, namely about hand hygiene, and have access to the existing guidelines, in order to minimize potential discrepancies in training that may negatively affect the safety, quality, and effectiveness of care delivery ${ }^{(10)}$.

With regard to aspects related to hand hygiene information and promotion, $62 \%$ of the nurses considered that the existing materials (posters, leaflets, etc.) were adequate, which is not in line with the national audit report, according to which these materials were displayed in $94.4 \%$ of healthcare units ${ }^{(9)}$.

\section{Limitations of the study}

This study requires further research on the topic, particularly in Portugal, given the low number of studies identified while preparing this study. The chosen sampling technique (convenience, non-probability) has limitations which were 
overcome by including participants from multiple internal medicine units, resulting in a heterogeneous sample. Data were collected using a questionnaire, which did not allow implementing the results directly into clinical practice. For these reasons, new studies should be developed with the purpose of identifying and observing nurses' perceptions and behaviors during care delivery and comparing them with the results obtained in this study.

\section{Contributions to Nursing and Health Policies}

It is necessary to rethink and restructure HAI control and prevention in hospital settings, with a focus on both individual and institutional responsibilities, particularly in terms of hand hygiene given its importance to the safety and quality of care delivery ${ }^{(2,4,10)}$. Therefore, institutional policies must be reformulated without neglecting each health professional's responsibility for continuously improving his/her knowledge and skills on this topic ${ }^{(2,5)}$. However, managers should play a proactive and active role in the creation of effective horizontal and vertical communication channels, as well as develop and implement quality control mechanisms that focus on the importance of hand hygiene in clinical settings, thus contributing to improve the levels of adherence $\mathrm{e}^{(2,4,10)}$.

\section{CONCLUSION}

It is necessary to find strategies that promote a safe and efficient hand hygiene management among nurses, which will ultimately contribute to collective health by significantly reducing the practices and behaviors that are not recommended in institutional guidelines. In addition, several challenges emerge as determining factors to achieve higher levels of adherence to hand hygiene among nurses, as well as to ensure a safe and quality care delivery: continuous and mandatory training, adequate staffing and nurse-to-patient ratio, and restructuring of the clinical areas with more suitable resources and areas for hand hygiene. However, institutional efforts should be developed to support the role of key players, such as unit managers and supervisors, in combining the efforts of all health professionals towards the adoption of common hand hygiene practices in the key moments identified in the literature.

\section{FUNDING}

This study was financed by national funds through the Foundation for Science and Technology, I.P., under Project No. UID/DTP/00742/2013.

\section{REFERENCES}

1. Portugal. Direção Geral de Saúde. Prevenção e Controlo de Infeções e de Resistência aos Antimicrobianos em Números - 2015. Direção-Geral da Saúde, Serviços de Informação e Análise [Internet]. 2016 [cited 2017 Jun 18]. Available from: https://www. dgs.pt/estatisticas-de-saude/estatisticas-de-saude/publicacoes/portugal-controlo-da-infecao-e-resistencia-aos-antimicrobianos-emnumeros-2015-pdf.aspx

2. World Health Organization. WHO. Guidelines on core components of infection prevention and control programmes at the national and acute health care facility level. WHO Document Production Services, Geneva, Switzerland [Internet]. 2016 [cited 2017 Jun 18]. Available from: http://apps.who.int/iris/bitstream/10665/251730/1/9789241549929-eng.pdf?ua=1

3. Pires FV, Tipple AFV, Freitas LR, Souza ACS, Pereira MS. Moments for hand hygiene in Material and Sterilization Center. Rev Bras Enferm [Internet]. 2016 [cited 2017 Jun 18] 69(3):511-5. Available from: http://www.scielo.br/pdf/reben/v69n3/en_0034-7167reben-69-03-0546.pdf

4. World Health Organization. WHO. Global Guidelines for the Prevention of Surgical Site Infection. World Press. Geneva, Switzerland [Internet]. 2016 [cited 2017 Jun 18]. Available from: http://www.who.int/gpsc/ssi-prevention-guidelines/en/

5. Graveto J, Fernandes E, Rebola R, Costa P. Higiene das mãos: adesão dos enfermeiros após processo formativo. Rev Bras Enferm. Forthcoming. 2017.

6. Silva M. Controlo de infeção em Portugal: evolução e atualidade. Rev Salutis Sci[Internet]. 2013 [cited 2017 Jun 18];5. Available from: http://www.salutisscientia.esscvp.eu/Site/download.aspx?artigoid = 31063

7. Teal K. The Hawthorne Effect at work. Infect Control Today [Internet]. 2016 [cited 2017 Jun 18]. Available from: http://www. infectioncontroltoday.com/articles/2016/09/the-hawthorne-effect-at-work.aspx

8. Portugal. Direção-Geral de Saúde. Programa de Prevenção e Controlo de Infeções e de Resistência aos Antimicrobianos: Prevenção e Controlo de Infeções e de Resistência aos Antimicrobianos em Números - 2015[Internet]. 2016 [cited 2017 Sep 13]. Available from: https:// www.dgs.pt/estatisticas-de-saude/estatisticas-desaude/publicacoes/portugal-controlo-da-infecao-e-resistencia-aos-antimicrobianosemnumeros-2015-pdf.aspx

9. Portugal. Direção-Geral de Saúde. Relatório Auditoria às Precauções Básicas de Controlo de Infeção e Monitorização da Higiene das Mãos Análise Evolutiva: 2014 - 2015. [Internet]. 2016 [cited 2017 Jun 18]. Available from: https://www.dgs.pt/documentose-publicacoes/relatorio-da-auditoria-as-precaucoes-basicas-de-controlo-de-infecao-e-monitorizacao-da-higiene-das-maos-analiseevolutiva-2014-2015-pdf.aspx

10. Portugal. Direção Geral de Saúde. Precauções Básicas do Controlo da Infeção (PBCI). Direção-Geral da Saúde, Departamento da Qualidade na Saúde [Internet]. 2013 [cited 2017 Jun 18]. Available from: https://www.dgs.pt/documentos-e-publicacoes/ 
relatorio-da-auditoria-as-precaucoes-basicas-de-controlo-de-infecao-e-monitorizacao-da-higiene-das-maos-analise-evolutiva2014-2015-pdf.aspx

11. Ellen ME, Hughes $F$, Shach R, Shamian J. How nurses can contribute to combating antimicrobial resistance in practice, research and global policy. Int J Nurs Stud[Internet]. 2017 [cited 2017 Jun 18];71:a1-a3. Available from: http://www.journalofnursingstudies. com/article/S0020-7489(17)30059-7/pdf

12. Portugal. Direção-Geral de Saúde. Prevenção e controlo de infeções e de resistência aos antimicrobianos em números - 2014 [Internet]. 2014 [cited 2017 Jun 18]. Available from:https://www.dgs.pt/estatisticas-de-saude/estatisticas-desaude/publicacoes/ portugal-controlo-da-infecao-e-resistencia-aos-antimicrobianosem-numeros-2014-pdf.aspx

13. Jimmieson N, Tucker M, White K, Liao J, Campbell M, Brain D, et al. The role of time pressure and different psychological safety climate referents in the prediction of nurses' hand hygiene compliance. Safety Sci[Internet] 2016 [cited 2017 Jun 18];82:29-43. Available from: http://www.sciencedirect.com/science/article/pii/S0925753515002271

14. Whitby M, McLaws M, Ross M. Why healthcare workers don't wash their hands: a behavioral explanation infection control \& hospital epidemiology [Internet]. 2006 [cited 2017 Jun 18];27(05):484-92. Available from: http://www.jstor.org/stable/10.1086/503335 